\title{
Telomerase activity in bleomycin-induced epithelial cell apoptosis and lung fibrosis
}

\author{
Z.G. Fridlender*, P.Y. Cohen*, O. Golan*, N. Arish*, \\ S. Wallach-Dayan* and R. Breuer**\#
}

ABSTRACT: Epithelial cell injury and apoptosis are recognised as early features in idiopathic pulmonary fibrosis and bleomycin-induced fibrosis in mice. Telomerase is a known apoptosisalleviating factor. The role of telomerase was studied during bleomycin-induced lung epithelial cell (LEC) apoptosis in vitro in a mouse LEC line, and in vivo in LECs isolated from bleomycintreated mice.

The current authors evaluated changes in murine telomerase reverse transcriptase (mTERT) mRNA levels and changes in telomerase activity with the TRAPeze Detection Kit, telomeric length with the TeloTTAGGG Telomere Length Kit, and LEC apoptosis with FACScan and 4,6-diamino-2phenylindole dihydrochloride stain.

There was a significant elevation in mTERT mRNA and a transient $41 \%$ increase in telomerase activity $24 \mathrm{~h}$ after in vitro bleomycin treatment. At $72 \mathrm{~h}$, telomerase activity had fallen to $26 \%$ below levels in untreated cells. Reduction of telomerase activity over time, or by direct inhibition, significantly elevated LEC apoptosis. No change in average telomeric length was noted. In vivo, telomerase activity of LECs from bleomycin-treated mice increased at 7 and 14 days.

In conclusion, telomerase activity may play a protective role against robust bleomycin-induced lung epithelial cell apoptosis. Moreover, stabilising telomerase activity may decrease epithelial cell apoptosis and the resulting lung fibrosis.

KEYWORDS: Apoptosis, bleomycin, epithelial cells, fibrosis, lung, telomerase

B leomycin-induced lung injury in mice is a well-established model of lung fibrosis [1]. Following in vivo instillation of bleomycin to the trachea, apoptosis is induced in lung epithelial cells, which lose their potential to reconstitute a normal alveolar surface [2]. When this occurs, normal lung epithelial cells are replaced with fibroblasts, leading to fibrosis [2-4]. Inhibition of apoptosis could diminish epithelial cell replacement by fibroblasts, and thus reduce lung fibrosis.

Telomere length is maintained by telomerase, a ribonucleoprotein RNA-dependent DNA polymerase complex. Telomerase consists of an RNA template and a catalytic protein, telomerase reverse transcriptase (TERT) [5]. Maintenance of telomerase activity is essential for the survival of proliferating cells [6-8]. Knockout mice lacking the gene for TERT express higher levels of apoptosis and show liver fibrosis, both of which can be repaired by the introduction of telomerase [9].

The current authors have recently confirmed that bleomycin causes apoptosis of lung epithelial cells in vitro in a time- and dose-dependent manner [10], and also reported the specific induction of epithelial cell apoptosis by myofibroblasts from fibrotic lungs via the Fas/Fas ligand pathway [11]. The aim of the present study was to evaluate telomerase activity in bleomycintreated lung epithelial cells (LECs) and the resulting effect on apoptosis in bleomycin-treated mouse lung epithelial (MLE) cells. It was hypothesised that bleomycin injury would result in a reduction of telomerase activity in lung epithelial cells, in contrast to in fibroblasts, and thus an increase in LEC apoptosis.

It was found that bleomycin causes an initial increase, and then a reduction, in telomerase activity controlled, at least in part, at the mRNA level. When telomerase activity is diminished, significant apoptosis of epithelial cells is initiated. With further disruption of telomerase activity, apoptosis occurs at significantly higher levels.

In order to establish the relevance of these findings to the pathological process of lung fibrosis, the current authors evaluated telomerase activity in vivo in an experimental model of murine bleomycin-induced fibrosis. An early

\section{AFFILIATIONS}

*Lung Cellular and Molecular Biology Laboratory, Institute of Pulmonary Medicine, Hadassah Hebrew University Medical Center, Jerusalem, Israel.

"Dept of Pathology, Boston University School of Medicine, Boston, MA, USA.

CORRESPONDENCE

Z.G. Fridlender

Institute of Pulmonology

Hadassah - Hebrew University

Medical Center

POB 12000

Jerusalem 91120

Israel

Fax: 97226435897

E-mail: fridlender@hadassah.org.il

Received:

January 242007

Accepted after revision:

April 302007

\section{SUPPORT STATEMENT}

This study was supported in part by grants from the David Shainberg Fund, the joint research fund of the Hebrew University and Hadassah Medical Center (Jerusalem, Israel), and the Dahlia Greidinger AntiCancer Fund.

STATEMENT OF INTEREST None declared.

European Respiratory Journal Print ISSN 0903-1936 Online ISSN 1399-3003 
reduction of telomerase activity in lung epithelial cells isolated from bleomycin-treated mice was found. This was followed by a pattern similar to that encountered in vitro, with significant elevation of telomerase activity in the surviving cells, followed eventually by a reduction back to baseline levels.

\section{MATERIALS AND METHODS \\ Cell line and culture}

Experiments were conducted with the murine type II, simian vacuolating virus-40-transformed LEC line (ATCC, MLE-15). This extensively used cell line [11-13] was maintained in HITES (Ham's F12, insulin, transferin, $\beta$-estradiol and sodium selenite) medium, supplemented with $2 \%$ foetal bovine serum (Biological Industries, Beit Haemek, Israel).

\section{Animals}

Male, 11-12-week-old, C57B1/6 mice (Harlan SpragueDawley, Indianapolis, IN, USA), each weighing 25-35 g, were used. The local committee for animal experiments (Hadassah Hebrew University Medical Center, Jerusalem, Israel) approved all animal care and experimental protocols.

\section{Reagents}

The reagents used were: propidium iodide (PI) stock solution, $1 \mathrm{mg} \cdot \mathrm{mL}^{-1}$ (Calbiochem, La Jolla, CA, USA) in PBS; fluorescein isothiocyanate (FITC)-conjugated Annexin V (BD Pharmingen, San Diego, CA, USA); bleomycin (ASTA Medica, Frankfurt am Main, Germany); tetra( $N$-methyl-4-pyridyl)-porphyrin chloride (TMPyP4), a G-quadruplex-intercalating porphyrin telomerase inhibitor (Calbiochem, Cambridge, MA, USA); 4,6diamino-2-phenylindole dihydrochloride (DAPI) stain (SigmaAldrich, St Louis, MO, USA); pentobarbitol 6\% (Shoresh Pharm, Jerusalem, Israel); dispase II (Roche Diagnostics $\mathrm{GmbH}$, Mannhein, Germany); Dulbecco/Vogt modified Eagle's minimal essential medium (DMEM; Sigma-Aldrich); DNase (Sigma-Aldrich); 4\% paraformaldehyde (SigmaAldrich); and saponin buffer (Sigma-Aldrich).

\section{Exposure of MLE line cells to bleomycin}

MLE cells suspended in HITES medium were incubated with or without 0.1 unit $\cdot \mathrm{mL}^{-1}$ bleomycin. This bleomycin dose was selected based on previous kinetic studies in the current authors' laboratory, because at $24 \mathrm{~h}$ it induces significant, but not overwhelming, apoptosis [10]. After incubation, trypsin (Biological Industries) was added for adherent cell removal and the mixture was centrifuged $(253 \times g ; 10 \mathrm{~min})$. The pellet was resuspended for further evaluation and viable cells were counted using trypan blue (Sigma-Aldrich).

\section{Evaluation of apoptosis}

DAPI staining was used to assess the proportion of apoptotic cells, as previously described [12, 14]. After elution of the media, MLE cells were washed with PBS (5 min; room temperature). Cold methanol ( $2 \mathrm{~mL})$ was added to each plate, cells were reincubated $\left(30 \mathrm{~min} ;-20^{\circ} \mathrm{C}\right)$ and then rewashed, and sediment was placed on coverslips. DAPI stain $(100 \mu \mathrm{L}$ of $1 \mu \mathrm{g} \cdot \mathrm{mL}^{-1}$ ) was added to the coverslips, which were then incubated in the dark (15 min; room temperature), washed twice with PBS and dried. The coverslips were placed on slides that had been prepared in advance with $20 \mu \mathrm{L}$ of mounting solution. Slides were evaluated with a fluorescent microscope
(Axiovert 200; Carl Zeiss AG, Oberkochen, Germany) and data were analysed (Image-Pro Plus 4.1; MediaCybernetics, Silver Spring, MD, USA). At least 100 cells were randomly selected and counted from each slide, and the average percentage of apoptotic cells from all slides in each group was reported.

Flow cytometry analysis with FACScan (Becton Dickinson, Mountain View, CA, USA) was used in one of two ways as a second method to evaluate apoptosis, as follows.

1) Cells $\left(10^{6} \cdot \mathrm{mL}^{-1}\right)$ were incubated (15 $\mathrm{min}$; room temperature) with $5 \mu \mathrm{L} \cdot \mathrm{mL}^{-1}$ of FITC-conjugated Annexin V, collected and pelleted. PI $\left(1 \mu \mathrm{g} \cdot \mathrm{mL}^{-1}\right)$ was added to the cells (5 min; room temperature). Flow cytometry analysis (FL1/FITC-Annexin V plotted against FL2/PI-positive cells) was performed with FACScan, and data were analysed with CellQuest-ProTM software (Becton Dickinson). PI-positive cells were excluded from the presented data.

2) Due to the autofluorescence of TMPyP4, Annexin V measurement was not possible when TMPyP4 was used. In this situation, cells $\left(10^{6} \cdot \mathrm{mL}^{-1}\right)$ were evaluated for size and granularity (forward and side scatter) using FACScan. The population of apoptotic cells was characterised by their smaller size, implying apoptotic shrinkage, as well as their higher granularity, representing apoptotic cytoplasmic condensation, as previously reported $[15,16]$.

\section{RNA isolation}

Total cellular RNA was isolated from cell pellets using TRI Reagent (Sigma-Aldrich) supplemented by $1 \mu \mathrm{g} \cdot \mathrm{mL}^{-1}$ of glycogen, according to the manufacturer's protocol. To assess RNA integrity and verify the absence of a high molecular weight band representing contamination with genomic DNA, an aliquot of each sample was analysed by $1 \%$ agarose gel electrophoresis. RNA was also analysed by spectrophotometer for assessment of integrity, protein contamination (ratio of absorbance at $260 / 280 \mathrm{~nm}>1.8$ ) and quantification.

\section{Semiquantitative RT-PCR of mTERT}

RNA was reverse-transcribed to cDNA using an avian myeloblastosis virus reverse-transcription (RT)-based protocol with random primers, as well as poly $(\mathrm{dT})$ (Reverse Transcription System; Promega, Madison, WI, USA). From each sample, $1 \mu \mathrm{g}$ was uniformly used for RT. Taq DNA polymerase $(0.25 \mathrm{~mL}$; Roche Diagnostics $\mathrm{GmbH}$ ) was added to each tube following hot-start incubation $\left(5 \mathrm{~min}\right.$; $\left.95^{\circ} \mathrm{C}\right)$. This was followed by 40 cycles for murine TERT (mTERT) and 28 cycles for glyceraldehyde-3-phosphate dehydrogenase $(\mathrm{GAPDH})$ denaturation $\left(15 \mathrm{~s} ; 96^{\circ} \mathrm{C}\right)$, annealing $\left(20 \mathrm{~s} ; 65^{\circ} \mathrm{C}\right)$, extension $\left(1 \mathrm{~min} ; 72^{\circ} \mathrm{C}\right.$ ) and a final extension step (5 min). A total of $2 \mu \mathrm{L}$ of forward and reverse primer sequences (SigmaAldrich) were used as follows. Forward mTERT: 5'GGGAGATGGCCAAGAGCGTCTAAA-3'; reverse mTERT: 5'-CGGTGGGCTGGTGTTCAAGG-3'; forward GAPDH: 5'GTTGCCATCAATGACCCCTTC-3'; and reverse GAPDH: 5'CATGTGGGCCATGAGGTCCAC-3'. The number of cycles was predetermined to be the greatest number in which amplification was within the linear range. PCR products were analysed by electrophoresis on a $1 \%$ agarose gel stained with ethidium bromide (Sigma-Aldrich). The intensity of the fluorescent signal emitted by the PCR products was deter- 
mined by densitometry using a tabletop scanner (MultiAnalyst $^{\mathrm{TM}}$ PC Version 1.1; Bio-Rad Laboratories, Hercules, CA, USA). Data were analysed with the Fluor-S-Multilmager (Bio-Rad Laboratories). Each cDNA was amplified in triplicate, corrected to the level of GAPDH mRNA, and the median value used. Amplification was repeated with a smaller quantity of substrate if the densitometer signal was beyond the predetermined linear range.

\section{Detection of telomerase activity}

Telomerase activity was detected using the TRAPeze Telomerase Detection Kit (Intergen, Purchase, NY, USA), a PCR-based telomeric repeat amplification protocol (TRAP) method, as previously described [17]. Briefly, cell extracts were resuspended in CHAPS lysis buffer and combined with the reaction mix in RNase-free PCR tubes, adding a varied number of telomeric repeats onto the substrate oligonucleotide according to telomerase activity. Positive and negative controls were examined accordingly. Protein levels were evaluated using the Bradford method, and equal amounts of protein were evaluated. PCR amplification was then performed. Loading dye was added to each reaction tube, and the mixture was loaded onto a $12.5 \%$ nondenaturising SDS-PAGE gel. Following electrophoresis, the gel was stained with ethidium bromide, and detection was determined by densitometry using a tabletop scanner (Bio-Rad Laboratories). The total and relative quantities of telomerase product for each sample were calculated using the Fluor-S-MultiImager.

\section{Measurement of terminal restriction fragment (telomeric) length}

Telomeric length was determined as previously described [17, 18] using the TeloTTAGGG Telomere Length Assay Kit (Roche Diagnostics $\mathrm{GmbH}$ ). Briefly, genomic DNA was isolated and digested with Hinf1/Rsa, DNA fragments were separated by electrophoresis on agarose gel, and Southern blot transfer was performed. The membrane was hybridised with a telomerespecific digoxigenin (DIG)-labelled probe, incubated with antiDIG alkaline phosphatase, and assessed with chemiluminescence detection (Kodak X-OMAT 2000 Processor; Kodak, Rochester, NY, USA). Average telomeric length was determined using Telometric 1.2 (Fox Chase Cancer Center, Philadelphia, PA, USA).

\section{Telomerase inhibition}

Telomerase activity was inhibited in MLE cells using $1.5 \mathrm{mM}$ of TMPyP4, and inhibition was confirmed using the TRAPeze Telomerase Detection Kit.

\section{Intratracheal instillation of animals}

Intratracheal instillation of bleomycin or saline to mice was performed as has been previously described [1, 19]. Briefly, mice were anaesthetised intraperitoneally. The trachea was exposed and a metal cannula was carefully inserted into the trachea. Bleomycin $(0.08 \mathrm{mg})$ in $0.1 \mathrm{~mL}$ of $0.9 \%$ saline, or saline alone was injected.

\section{LEC isolation for ex vivo culture}

LECs were isolated as has been previously reported [11]. Briefly, animals were sacrificed by aortic transection while under pentobarbitol $6 \%$ anaesthesia. The lungs were filled with
$3 \mathrm{~mL}$ dispase II and allowed to collapse. Low-melt agarose $(0.5 \mathrm{~mL})$ was then infused, and lungs were covered with ice for $2 \mathrm{~min}$. The lungs were excised from the animals and incubated in $1 \mathrm{~mL}$ dispase II in a 12-mL polypropylene culture tube (45 min; room temperature). The lungs were transferred to $7 \mathrm{~mL}$ DMEM with $0.01 \%$ type II DNase in a $60-\mathrm{mm}$ petri dish. Digested tissue was gently swirled for 5-10 min. The resulting suspension was filtered through $100-\mu \mathrm{m}$ and $40-\mu \mathrm{m}$ Falcon strainers, and then through a $22-\mu \mathrm{m}$ nylon mesh, centrifuged $(142 \times g ; 12 \mathrm{~min}$; room temperature) and resuspended in culture medium. The cells were placed on culture plates previously coated with mouse anti-CD45 and mouse antiCD16/32 monoclonal antibodies (IQ Products, Groningen, the Netherlands). Cells were incubated $\left(2 \mathrm{~h} ; 37^{\circ} \mathrm{C}\right)$, transferred to new uncoated culture plates $\left(45 \mathrm{~min} ; 37^{\circ} \mathrm{C}\right)$ and collected by centrifugation.

\section{Evaluation of isolated LECs for purity by flow cytometry}

In order to assess the purity of isolated epithelial cells, both extracellular and intracellular markers were evaluated.

\section{Extracellular staining}

LECs were fixed with $4 \%$ paraformaldehyde (10 min; room temperature) and then washed with PBS. LECs were then incubated (30 min; room temperature) with $10 \mu \mathrm{L} / 100 \mu \mathrm{L}$ of one of four antibodies: 1) FITC-conjugated lymphocyte marker (anti-CD3, IQ Products); 2) FITC-conjugated leukocyte marker (anti-CD31; BD Pharmingen); 3) FITC-conjugated macrophage marker (F4/80; Serotec, Raleigh, NC, USA); and 4) type I epithelial cell marker (AQ5, non-FITC conjugated, with addition of secondary antibody FITC-conjugated anti-goat; Jackson Immunoresearch Laboratories, West Grove, PA, USA). The cells were washed twice in saponin buffer and analysed by flow cytometry.

\section{Intracellular staining}

Cells were washed with $0.1 \%$ saponin buffer and then incubated (30 min; room temperature) with $1 \mu \mathrm{L} / 100 \mu \mathrm{L}$ of one of the following antibodies: 1) type II epithelial markers (anti-surfactant protein (SP)B or anti-SPC; Chemicon, Temecula, CA, USA); or 2) myofibroblast marker (anti- $\alpha$ smooth muscle actin FITC conjugate; Chemicon). For SPB and SPC staining, $1 \mu \mathrm{g} / 100 \mu \mathrm{L}$ of FITC-conjugated anti-rabbit antibodies (Jackson Immunoresearch Laboratories) was added and cells were reincubated (30 min; room temperature). The cells were then washed twice in saponin buffer and analysed by flow cytometry.

Following this two-step evaluation, $\sim 90 \%$ of the isolated cells were found to be type I or II lung epithelial cells.

\section{Statistical analysis}

Analysis of variance was performed with the Kruskal-Wallis test for nonparametric data. When Kruskal-Wallis tests of comparability were statistically significant, Mann-Whitney comparisons with Holms sequential Bonferroni corrected pvalues were performed. In order to determine whether relative telomerase activity was consistently greater or less than baseline, the data were dichotomised. One sample Chi-squared test was performed, comparing the observed distribution with an expected random distribution. A p-value $<0.05$ was considered significant. 


\section{RESULTS}

\section{Bleomycin modifies telomerase activity in vitro}

In order to study the effects of bleomycin on telomerase activity of LECs, MLE cells were exposed to bleomycin for 24, 48 or $72 \mathrm{~h}$. Cells were collected and resuspended. Viable cells were counted using trypan blue in order to exclude necrotic cells. A similar number of viable cells were taken for evaluation of telomerase activity from each group of bleomycin-treated and untreated cells. Telomerase activity increased in bleomycin-treated cells, compared with untreated control cells, by a mean of 41 and $12 \%$ at 24 and $48 \mathrm{~h}$ respectively. The mean activity then decreased to $26 \%$ below control levels at $72 \mathrm{~h}$ (fig. 1). At $96 \mathrm{~h}$, bleomycin caused excessive cell death, precluding measurement in four out of six experiments. However, in two successful experiments the mean reduction of telomerase activity at $96 \mathrm{~h}$ in bleomycintreated compared with control cells was $43 \%$ (data not shown). Figure 1 shows the level of telomerase activity in bleomycintreated compared with untreated control cells at each time point. A regression analysis of the percentage change versus time of bleomycin exposure yielded the following linear equation: ratio $=1.771-0.307 \times$ exposure days $\quad\left(r^{2}=0.83\right.$; $\mathrm{p}=0.023)$. The level of telomerase activity in bleomycin-treated cells compared with untreated control cells was significantly higher at $24 \mathrm{~h}(\mathrm{p}=0.014)$ and lower at $72 \mathrm{~h}(\mathrm{p}=0.014)$.

\section{Bleomycin increases expression of mTERT mRNA}

The transcriptional regulation of the catalytic component of telomerase, mTERT, is recognised as one of the major ratelimiting steps in the induction of telomerase activity [5]. In order to assess the regulation level of telomerase activity in bleomycin-treated MLE cells, mTERT mRNA levels were measured. Cells were exposed to bleomycin for 24,48 or $72 \mathrm{~h}$. mTERT mRNA in bleomycin-treated MLE cells was measured by semiquantitative RT-PCR, and compared with the median level of untreated control cells at each time point. Bleomycin

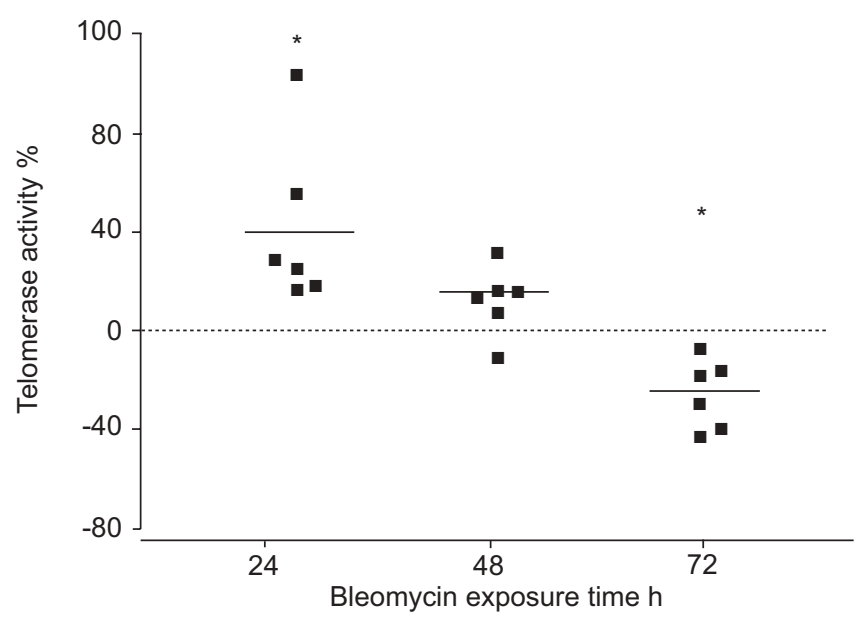

FIGURE 1. Bleomycin modifies telomerase activity. Telomerase activity was assessed in bleomycin-treated and untreated mouse lung epithelial cells using the TRAPeze Telomerase Detection Kit. The percentage change of telomerase activity in bleomycin-treated cells, compared with untreated control cells, at 24, 48 and $72 \mathrm{~h}$ is presented. Each point represents an independent comparison between bleomycin-treated and control cells. *: $p<0.05$. induced a substantial increment of mTERT mRNA at $24 \mathrm{~h}$. There was some elevation at $48 \mathrm{~h}$, although considerably less significant. The level of mTERT mRNA in bleomycin-treated MLE cells returned nearly to control levels at $72 \mathrm{~h}$ (fig. 2).

\section{Bleomycin does not change average telomeric length}

Telomerase inhibition can induce apoptosis in several ways, but telomere shortening is generally accepted to be the primary mechanism [7]. In order to assess bleomycin-induced changes in telomeric length, the average terminal restriction fragment length was measured using the TeloTTAGGG Telomere Length Assay Kit (Roche Diagnostics $\mathrm{GmbH}$ ). In three independent experiments, there was no difference between average telomeric length in MLE cells exposed to bleomycin compared with controls at 24 or $72 \mathrm{~h}$. The results shown in figure 3 are representative of four experiments.

\section{Elevation in telomerase activity delays robust apoptosis}

The current authors performed kinetic evaluations of telomerase activity levels and apoptosis rates in bleomycin-treated MLE cells at 6-48 h. Telomerase activity was assessed with the TRAPeze Telomerase Detection Kit, and the percentage of apoptotic cells was estimated using double staining with Annexin V and PI. A representative experiment is shown in figure 4. There was an initial elevation of relative telomerase activity in bleomycin-treated cells, followed by a decrease in activity that was associated with a significant increase in apoptosis.

\section{Inhibition of telomerase activity by TMPyP4 increases epithelial cell apoptosis}

TMPyP4 is a known G-quadriplex inhibitor of telomerase activity [20]. TMPyP4 exposure alone caused apoptosis in MLE cells at rates similar to bleomycin exposure (data not shown). In order to establish the relationship between changes in telomerase activity and apoptosis, bleomycin-treated MLE cells

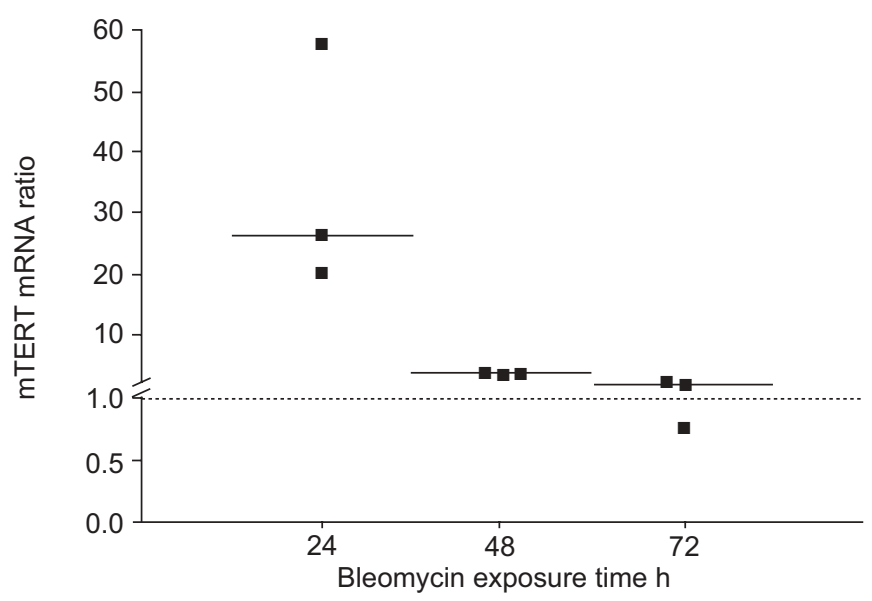

FIGURE 2. Bleomycin increases expression of murine telomerase reverse transcriptase (mTERT) mRNA. The level of mTERT mRNA was assessed in mouse lung epithelial cells using semiquantitative reverse transcription-PCR. The ratio between the level of mTERT mRNA in bleomycin-treated cells and the median level of mTERT mRNA in untreated control cells, at each time point, both adjusted to glyceraldehyde-3-phosphate dehydrogenase, is presented. Each point represents an independent experiment. ...... point of equality between the two groups. 


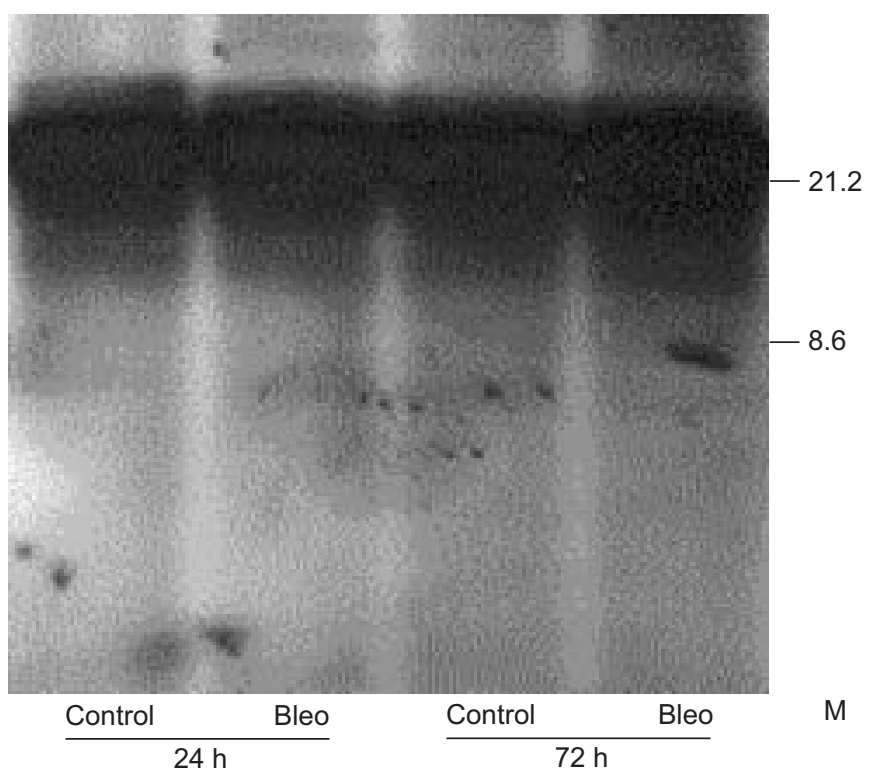

FIGURE 3. Bleomycin does not change telomeric length. A representative experiment showing the results of average telomeric length measurements at 24 and $72 \mathrm{~h}$. No difference was seen between the calculated average telomeric length in bleomycin-treated mouse lung epithelial cells (Bleo) and untreated control cells. M: size marker

were exposed to TMPyP4 for $24 \mathrm{~h}$. TMPyP4 was confirmed to inhibit the bleomycin-induced elevation in telomerase activity using the TRAPeze Telomerase Detection Kit (data not shown). Apoptosis, evaluated using the DAPI stain, was higher in bleomycin-treated MLE than untreated control cells, and increased appreciably in bleomycin-treated MLE cells that were exposed to the telomerase inhibitor TMPyP4 (figs 5a-c). For quantification, the proportion of apoptotic cells was calculated in 200 random cells on every DAPI-stained slide in four independent experiments. The mean proportion of MLE apoptotic cells was $81.3 \%$ in bleomycin and TMPyP4treated cells compared with $43.4 \%$ in cells treated with bleomycin alone $(\mathrm{p}<0.05$; fig. $5 \mathrm{~g})$.

Apoptosis was further evaluated using flow cytometry analysis of size and granularity as previously described [15, 21]. Cells exposed to both bleomycin and telomerase inhibition had a significantly higher proportion of apoptotic cells when compared with treatment with bleomycin alone (fig. 5h). Representative dot plots are presented in figures $5 \mathrm{~d}-\mathrm{f}$.

\section{Bleomycin modifies telomerase activity in LECs in vivo}

Epithelial cells were isolated from mouse lungs 1, 3, 7, 14 and 21 days after intratracheal instillation of bleomycin or saline. The development of fibrosis was confirmed in bleomycintreated mice, as previously reported [1]. Changes in telomerase activity of LEC isolated from bleomycin-treated compared with saline-treated mice are presented in figure 6 . Telomerase activity decreased at day 3 by a mean of $59 \%(p=0.046)$. At day 7 , there was a mean elevation of $36 \%$ in telomerase activity in surviving LEC $(p=0.046)$, with a further increase at day 14 by a mean of $68 \%(p=0.014)$. No significant change in telomerase activity in bleomycin-treated compared with control mice was found at day 21, when the fibrotic process subsided (fig. 6).

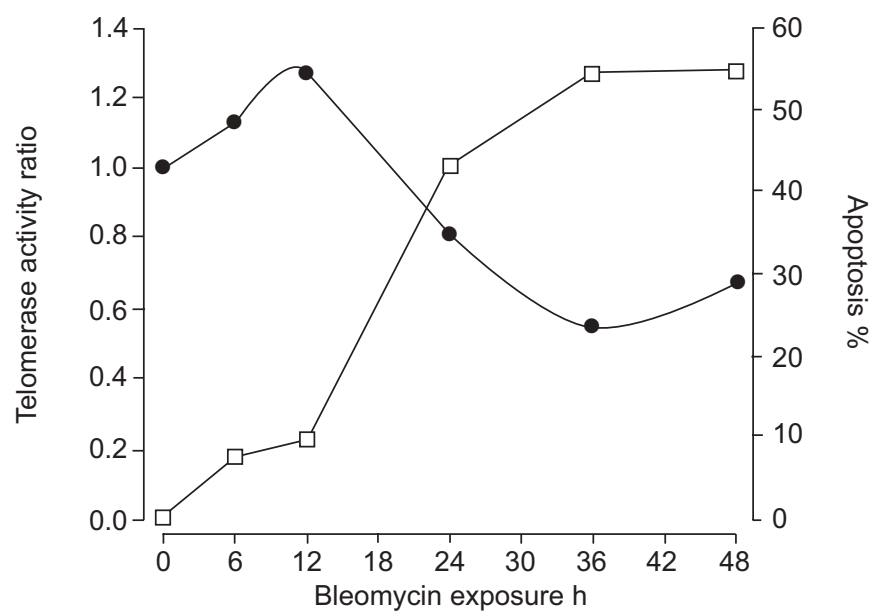

FIGURE 4. Elevation in telomerase activity delays robust apoptosis Telomerase activity at 6-48 h, assessed with the TRAPeze Telomerase Detection Kit, is expressed as the ratio of bleomycin-treated to untreated control mouse lung epithelial cells $(\bullet)$. The percentage of apoptosis in bleomycin-treated cells was evaluated with Annexin V/propidium iodide staining ( $\square$ )

\section{DISCUSSION}

In the present study, the role of telomerase during bleomycininduced apoptosis was studied in LECs in vitro and LECs isolated from mice with bleomycin-induced lung fibrosis in vivo.

It was found that bleomycin causes an initial elevation of telomerase activity, followed by a reduction, in MLE cells in vitro. Initial bleomycin-induced apoptosis has occurred at $12 \mathrm{~h}$, as telomerase activity increases. Subsequent reduction of telomerase activity over time results in substantially increased apoptosis (fig. 1)

In order to establish the relevance of these findings to the evolution of lung fibrosis, telomerase activity was evaluated in vivo in LECs isolated from bleomycin-treated mice. At day 7 , and even more so at day 14, LECs isolated from bleomycintreated mice showed a significant elevation of telomerase activity compared with LECs from saline-treated control mice. Increased telomerase activity is possibly a mechanism that enables these cells to outlive the attack of neighbouring inflammatory and other effector cells. When the fibrotic process subsided, at day 21 , telomerase activity dropped down to the levels found in control mice.

Mounting evidence indicates that telomerase activity protects cells from apoptosis via multiple mechanisms [7, 8, 22, 23]. In the current study, the anti-apoptotic effects of telomerase was shown in murine lung epithelial cells, where a transient, bleomycin-induced elevation of telomerase activity contributed to a significant delay in bleomycin-induced apoptosis (fig. 4). KLAPPER et al. [24] reported a similar transient elevation in telomerase activity induced in human promyelocytic leukaemia HL60 cells by etoposide, another DNA-damaging agent.

Early apoptosis is mediated by the process of DNA damage $[10,25]$, and telomerase activity does not protect from apoptosis at these early time points. Telomerase activity increases only after apoptosis has initiated (fig. 4). It is possible that apoptosis is the trigger for the induction of telomerase as a 

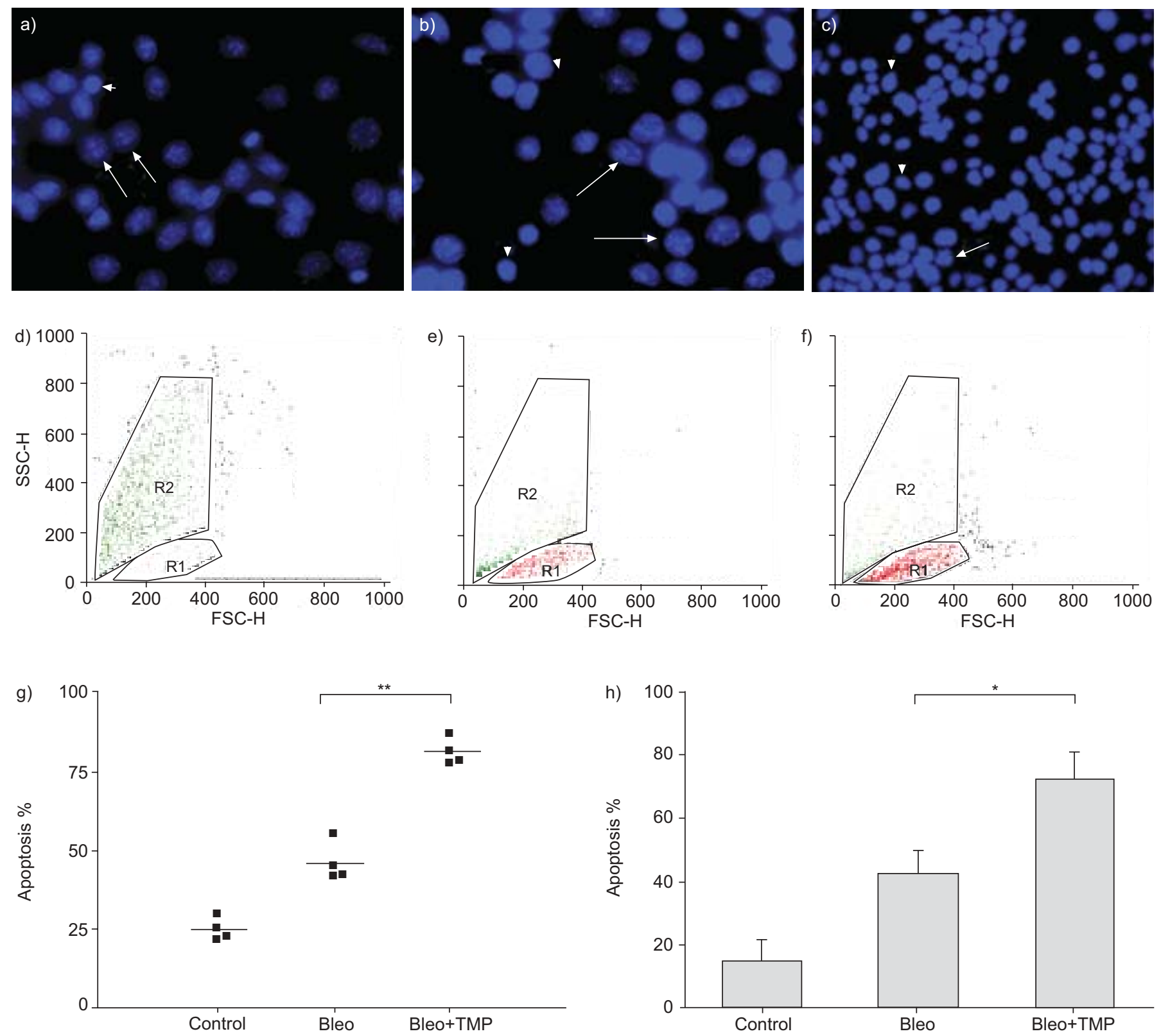

FIGURE 5. Inhibition of telomerase activity increases bleomycin-induced apoptosis. Using 4,6-diamino-2-phenylindole dihydrochloride (DAPI) stain for the identification of apoptotic cells, a) presents the increased percent of apoptotic cells in bleomycin- and tetra(N-methyl-4-pyridyl)-porphyrin chloride-treated mouse lung epithelial (MLE) cells (Bleo+TMP) at $24 \mathrm{~h}$, compared with, in b), cells treated solely with bleomycin (Bleo). c) Minimal apoptosis is shown in untreated control cells. The speckled cells are apoptotic (arrows), while the smooth cells are nonapoptotic (arrowheads). Also shown are representative FACS analyses of apoptosis at $24 \mathrm{~h}$ in the Bleo+TMP (d), Bleo (e) and control (f) cells. Apoptotic cells were identified by size and granularity (forward (FSC-H) and side (SSC-H) scatter height). R1: region of nonapoptotic cells; R2: region of apoptotic cells. g) The proportion of apoptotic MLE cells each represented by a point, at $24 \mathrm{~h}$ in four independent experiments using DAPI stain. Mean values are presented by solid lines. h) Mean \pm SD values representing the proportion of apoptotic MLE cells in seven independent experiments using FACS analysis. ${ }^{*}$ : $p<0.05 ;{ }^{* *}: p<0.01$.

defence mechanism from bleomycin-induced robust apoptosis. Therefore, the initial increase in bleomycin-induced telomerase activity, possibly mediated by apoptosis, may protect MLE cells from further apoptosis. Indeed, when the bleomycininduced increase in telomerase activity diminishes over time (fig. 1), the level of bleomycin-induced apoptosis increases significantly. The fact that robust apoptosis is induced by specific inhibition of telomerase with TMPyP4 (fig. 5) strengthens the hypothesis that this response is not merely correlative.
The current authors have previously shown that bleomycin causes significant DNA damage in MLE cells [10]. MASUTOMI et al. [26] showed that suppression of human TERT abrogates the cellular repair response to DNA double-strand breaks. It is therefore reasonable to assume that telomerase activity is elevated as part of the cellular reaction to that damage. The present work is further supported by the results of RuBio et al. [27], who showed that telomerase expression and elevation of its activity increased the resistance of cell lines to bleomycin. Taken 


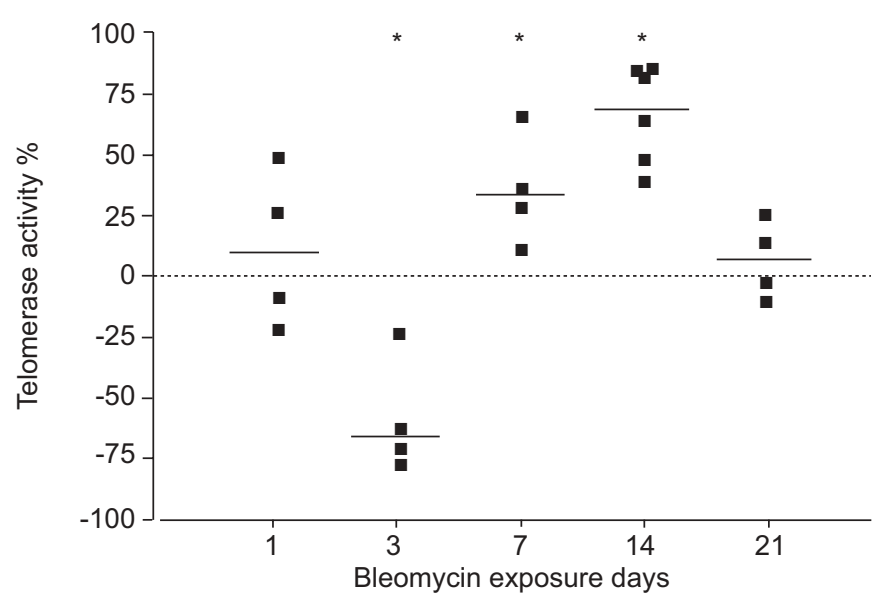

FIGURE 6. Bleomycin modifies telomerase activity in lung epithelial cells (LECs) in vivo. Telomerase activity was assessed in LECs isolated from bleomycinand saline-treated (control) mice using the TRAPeze Telomerase Detection Kit. The percentage change in telomerase activity of LECs isolated from bleomycin-treated in relation to saline-treated control mice at 1, 3, 7, 14 and 21 days post intratracheal instillation is presented. Each point represents an independent value. *: $p<0.05$.

together, these results suggest that resistance to bleomycin injury could be related, at least partly, to the inhibition of apoptosis induced by the telomerase complex. The current authors' data analysis, using PI staining followed by flow cytometry, excludes necrotic and dying cells, as opposed to apoptotic cells. This process argues against the possibility that changes in telomerase activity are merely a toxic effect of bleomycin. Elevations in telomerase activity and mRNA support the concept that this reaction is part of an active phenomenon.

Telomere shortening is the main mechanism for apoptosis induction following telomerase inhibition [7]. Massive telomere loss has been shown to occur early in DNA-damageinduced apoptosis [28]. However, there is accumulating evidence to suggest that telomerase also plays an important role in protecting karyotypic stability, independent of its part in maintaining telomeric length [22]. RuBIO et al. [27] reported that resistance to injury was related to telomerase activity only in cell lines with short telomeres, suggesting that telomere shortening is the cause of apoptosis. In contrast, the current authors found no change in the average length of telomeres in bleomycin-treated MLE cells for up to $72 \mathrm{~h}$, a time by which significant apoptosis has typically occurred. This finding agrees with the accepted convention that telomere shortening is a slow-acting mechanism for apoptosis induction [5]. It is possible that a limited and more specific telomeric loss (i.e. in a specific chromosome) is responsible for the induction of robust LEC apoptosis. However, it is clear that general massive telomere loss is probably not primarily responsible for apoptosis induction in these cells. Two rapid mechanisms of telomerase activity have been described and could account for the protection from apoptosis without notable change in telomeric length. These are telomere capping $[7,29]$ and regulation of gene expression by telomerase [23]. Induction of telomerase activity has been shown to significantly influence the expression of several oncogenes [30], and the absence of telomerase could activate genes involved in apoptosis [7].

The transcriptional regulation of the catalytic component of telomerase expression is recognised as one of the major ratelimiting steps in the induction of telomerase activity [5]. The current authors have found a rapid, substantial elevation in mTERT mRNA as early as $24 \mathrm{~h}$ after treatment with bleomycin. The bleomycin-induced elevation in telomerase activity is therefore regulated, at least in part, by this transcription.

Measurement of telomere elongation was the method used to assess telomerase activity. These measurements revealed a modest increase in telomerase activity at $24 \mathrm{~h}$ (fig. 1) versus a substantial elevation of mTERT mRNA (fig. 2). The lack of correlation between these measurements supports the concept that telomerase protected LECs from apoptosis in a manner unrelated to telomere elongation and telomeric loss.

Increasing evidence suggests that lung epithelial cell apoptosis is an important contributor to bleomycin-induced lung fibrosis $[2,31]$. One of the main theories for the pathophysiology of idiopathic pulmonary fibrosis (IPF) is that injury to the pulmonary parenchyma causes epithelial cell damage and apoptosis [32]. Evidence of type II pneumocyte apoptosis in normal alveoli of IPF patients has been previously reported [33], and loss of alveolar epithelium, with failure of reepithelisation, was proposed to stimulate persistence and progression of fibrosis [32].

The current authors have recently shown that myofibroblasts, which are known to accumulate abundantly in the lungs of mice with bleomycin-induced fibrosis $[3,34]$, are not only collagen producers, but also function as effector cells [11]. It was also demonstrated that they induce apoptosis of lung epithelial cells in vivo, a possible mechanism for the prevention of lung tissue remodelling [11]. Apoptosis thus plays a role in the induction of fibrosis.

In the present work, it was found that telomerase activity may have a role in bleomycin-induced lung fibrosis in vivo. Shortly after bleomycin injury, telomerase activity in LECs decreases. However, at days 7 and 14, telomerase activity increases, enabling epithelial cell regeneration, while epithelial cells without elevated telomerase activity may have already undergone apoptosis. Since elevated telomerase activity has been repeatedly shown to assist cell survival $[7,8,22,23]$, it is to be expected that, during intensive fibrosis (on days 7 and 14), surviving epithelial cells have levels of telomerase activity that are higher than baseline (fig. 6). The current authors suggest that this elevation in telomerase activity is a cellular defence mechanism against active myofibroblast-induced LEC apoptosis.

In the past, the current authors have shown that the fibrotic process in bleomycin-treated C57Bl/6J mice subsides at day 21 [1]. It is therefore not surprising that, at this time point, when the lung regeneration process has advanced and elevation of telomerase activity confers no survival advantage, it returns to normal levels in the remaining epithelial cells.

The impact of bleomycin-induced injury on telomerase activity is different in lung fibroblasts and epithelial cells. NOZAKI et al. [4] noted a constant elevation in telomerase activity in fibroblasts following bleomycin instillation with extended life 
span. In contrast, the present study shows that epithelial cells have only a transient elevation of telomerase activity, followed by a significant reduction, resulting in robust apoptosis.

The most important question arising from the present work is the relationship between changes in telomerase activity and human lung fibrosis. Mutations in the telomerase complex are linked to dyskeratosis congenita, a rare, inherited syndrome of bone marrow failure [35]. Pulmonary fibrosis is a recognised manifestation of this syndrome [36]. Furthermore, strong support for the relationship between an altered telomerase complex and IPF has been very recently published, demonstrating that mutations in the genes encoding telomerase can appear in familial IPF [37]. The current authors' work on epithelial cells, together with other research carried out on fibroblasts [3, 8], suggests the possibility of a relationship between telomerase mutations and lung fibrosis. Therefore, changes in telomerase activity could alter the differential reaction of LECs and fibroblasts to lung injury.

The present results demonstrate that changes in telomerase activity, regulated at least in part by transcription, play a role in LEC apoptosis by a mechanism that is independent of telomere loss. The elevation of telomerase activity in LECs in vivo may represent an active defence process in surviving LECs against neighbouring myofibroblasts that may cause apoptosis of epithelial cells as part of the fibrotic process. Those epithelial cells that activate a defence mechanism, including, but probably not limited to, elevation of telomerase activity, could escape apoptosis, survive the injury and help reduce the extent of fibrosis.

In conclusion, a novel possibility is presented for regulation of DNA-damage-induced lung injury through modifying telomerase activity. Understanding the role of telomerase in the apoptosis of epithelial cells is an important step in the evaluation of lung injury and possibly of fibrosis related to DNA damage. Therefore, stabilising telomerase activity in lung epithelial cells may decrease epithelial cell apoptosis and eventual lung fibrosis. This hypothesis is strongly supported by the recent reports that mutations in genes encoding telomerase have been found in familial idiopathic pulmonary fibrosis [37].

\section{ACKNOWLEDGEMENTS}

The authors wish to thank S. Fraifeld (Hadassah - Hebrew University Medical Center) for her editorial assistance in the preparation of this manuscript.

\section{REFERENCES}

1 Izbicki G, Segel MJ, Christensen TG, Conner MW, Breuer R. Time course of bleomycin-induced lung fibrosis. Int J Exp Pathol 2002; 83: 111-119.

2 Simon A. Alveolar epithelial cells in pulmonary fibrosis. In: Phan SH, Thrall RS, eds. Pulmonary Fibrosis. New York, Marcel Dekker Inc., 1995; pp. 511-540.

3 Kuwano K, Hagimoto N, Kawasaki M, et al. Essential roles of the Fas-Fas ligand pathway in the development of pulmonary fibrosis. J Clin Invest 1999; 104: 13-19.

4 Nozaki Y, Liu T, Hatano K, Gharaee-Kermani M, Phan SH. Induction of telomerase activity in fibroblasts from bleomycin-injured lungs. Am J Respir Cell Mol Biol 2000; 23: $460-465$.

5 Cong YS, Wright WE, Shay JW. Human telomerase and its regulation. Microbiol Mol Biol Rev 2002; 66: 407-425.

6 Hamad NM, Banik SS, Counter CM. Mutational analysis defines a minimum level of telomerase activity required for tumourigenic growth of human cells. Oncogene 2002; 21: 7121-7125.

7 Mondello C, Scovassi AI. Telomeres, telomerase, and apoptosis. Biochem Cell Biol 2004; 82: 498-507.

8 Ren JG, Xia HL, Tian YM, Just T, Cai GP, Dai YR. Expression of telomerase inhibits hydroxyl radicalinduced apoptosis in normal telomerase negative human lung fibroblasts. FEBS Lett 2001; 488: 133-138.

9 Rudolph KL, Chang S, Millard M, Schreiber-Agus N, DePinho RA. Inhibition of experimental liver cirrhosis in mice by telomerase gene delivery. Science 2000; 287: 1253-1258.

10 Wallach-Dayan SB, Izbicki G, Cohen PY, Gerstl-Golan R, Fine A, Breuer R. Bleomycin initiates apoptosis of lung epithelial cells by ROS but not by Fas/FasL pathways. Am J Physiol Lung Cell Mol Physiol 2006; 290: L790-L796.

11 Golan-Gerstl R, Wallach-Dayan SB, Amir G, Breuer R. Epithelial cell apoptosis by Fas ligand-positive myofibroblasts in lung fibrosis. Am J Respir Cell Mol Biol 2007; 36: 270-275.

12 Chan HC, Kuo SC, Liu SC, Liu CH, Hsu SL. 4-Fluoro-Nbutylphenylacetamide: a synthetic phenylacetate derivative that upregulates $\mathrm{Bcl}-\mathrm{X}_{\mathrm{S}}$, activates caspase cascade and induces apoptosis in human squamous lung cancer $\mathrm{CH} 27$ cells. Cancer Lett 2002; 186: 211-221.

13 De Paepe ME, Mao Q, Chao Y, Powell JL, Rubin LP, Sharma S. Hyperoxia-induced apoptosis and fas/fasl expression in lung epithelial cells. Am J Physiol Lung Cell Mol Physiol 2005; 289: L647-L659.

14 Ramage L, Jones AC, Whelan CJ. Induction of apoptosis with tobacco smoke and related products in A549 lung epithelial cells in vitro. J Inflamm (Lond) 2006; 3: 3.

15 Healy E, Dempsey M, Lally C, Ryan MP. Apoptosis and necrosis: mechanisms of cell death induced by cyclosporine A in a renal proximal tubular cell line. Kidney Int 1998; 54: 1955-1966.

16 Holt SE, Norton JC, Wright WE, Shay JW. Comparison of the telomeric repeat amplification protocol (TRAP) to the new TRAP-eze telomerase detection kit. Methods Cell Sci 1996; 18: 237-248.

17 Bryan TM, Englezou A, Dunham MA, Reddel RR. Telomere length dynamics in telomerase-positive immortal human cell populations. Exp Cell Res 1998; 239: 370-378.

18 Hsu CP, Miaw J, Shai SE, Chen CY. Correlation between telomerase expression and terminal restriction fragment length ratio in non-small cell lung cancer-an adjusted measurement and its clinical significance. Eur J Cardiothorac Surg 2004; 26: 425-431.

19 Segel MJ, Aqeilan R, Zilka K, et al. Effect of IL-2-Bax, a novel interleukin-2-receptor-targeted chimeric protein, on bleomycin lung injury. Int J Exp Pathol 2005; 86: 279-288.

20 Izbicka E, Wheelhouse RT, Raymond E, et al. Effects of cationic porphyrins as G-quadruplex interactive agents in human tumor cells. Cancer Res 1999; 59: 639-644. 
21 Urech K, Scher JM, Hostanska K, Becker H. Apoptosis inducing activity of viscin, a lipophilic extract from viscum album 1. J Pharm Pharmacol 2005; 57: 101-109.

22 Chan SW, Blackburn EH. New ways not to make ends meet: telomerase, DNA damage proteins and heterochromatin. Oncogene 2002; 21: 553-563.

23 Smith LL, Coller HA, Roberts JM. Telomerase modulates expression of growth-controlling genes and enhances cell proliferation. Nat Cell Biol 2003; 5: 474-479.

24 Klapper W, Qian W, Schulte C, Parwaresch R. DNA damage transiently increases TRF2 mRNA expression and telomerase activity. Leukemia 2003; 17: 2007-2015.

25 Hay J, Shahzeidi S, Laurent G. Mechanisms of bleomycininduced lung damage. Arch Toxicol 1991; 65: 81-94.

26 Masutomi K, Possemato R, Wong JM, et al. The telomerase reverse transcriptase regulates chromatin state and DNA damage responses. Proc Natl Acad Sci USA 2005; 102: 8222-8227.

27 Rubio MA, Davalos AR, Campisi J. Telomere length mediates the effects of telomerase on the cellular response to genotoxic stress. Exp Cell Res 2004; 298: 17-27.

28 Ramirez R, Carracedo J, Jimenez R, et al. Massive telomere loss is an early event of DNA damage-induced apoptosis. J Biol Chem 2003; 278: 836-842.

29 Leonetti C, Amodei S, D'Angelo C, et al. Biological activity of the G-quadruplex ligand RHPS4 (3,11-difluoro-6,8,13trimethyl-8H-quino[4,3,2-kl]acridinium methosulfate) is associated with telomere capping alteration. Mol Pharmacol 2004; 66: 1138-1146.
30 Milyavsky M, Shats I, Erez N, et al. Prolonged culture of telomerase-immortalized human fibroblasts leads to a premalignant phenotype. Cancer Res 2003; 63: 7147-7157.

31 Selman M, King TE, Pardo A. Idiopathic pulmonary fibrosis: prevailing and evolving hypotheses about its pathogenesis and implications for therapy. Ann Intern Med 2001; 134: 136-151.

32 Noble PW, Homer RJ. Idiopathic pulmonary fibrosis: new insights into pathogenesis. Clin Chest Med 2004; 25: 749-758.

33 Barbas-Filho JV, Ferreira MA, Sesso A, Kairalla RA, Carvalho CR, Capelozzi VL. Evidence of type II pneumocyte apoptosis in the pathogenesis of idiopathic pulmonary fibrosis (IPF)/usual interstitial pneumonia (UIP). J Clin Pathol 2001; 54: 132-138.

34 Zhang K, Rekhter MD, Gordon D, Phan SH. Myofibroblasts and their role in lung collagen gene expression during pulmonary fibrosis. A combined immunohistochemical and in situ hybridization study. Am J Pathol 1994; 145: 114-125.

35 Mason PJ, Wilson DB, Bessler M. Dyskeratosis congenita a disease of dysfunctional telomere maintenance. Curr Mol Med 2005; 5: 159-170.

36 Utz JP, Ryu JH, Myers JL, Michels VV. Usual interstitial pneumonia complicating dyskeratosis congenita. Mayo Clin Proc 2005; 80: 817-821.

37 Armanios MY, Chen JJ, Cogan JD, et al. Telomerase mutations in families with idiopathic pulmonary fibrosis. N Engl J Med 2007; 356: 1317-1326. 